\title{
Desempenho produtivo e bioquímico de alface crespa sob diferentes ambientes de cultivo
}

Productive and biochemical performance of curly lettuce cultivars under different growing environments

\author{
A. S. Do Nascimento ${ }^{1 *}$; R. H. Silva ${ }^{2}$; M. M. Echer ${ }^{3}$; P. W. R. Coutinho ${ }^{4}$, D. K. \\ Klein ${ }^{5}$ \\ ${ }^{1}$ Laboratório de Controle Alternativo, Universidade Estatual do Maringá, 87020-900, Maringá-Paraná, Brasil \\ ${ }^{2}$ Laboratório de Fitopatologia, Universidade Estadual do Oeste do Paraná, 85960-000, Marechal Cândido Rondon- \\ Paraná, Brasil \\ ${ }^{3}$ Universidade Estadual do Oeste do Paraná, 85960-000, Marechal Cândido Rondon-Paraná, Brasil \\ ${ }^{4}$ Autônomo, 68650-000, Capitão Poço-Pará, Brasil \\ ${ }^{5}$ Biogenesis - Centro de Pesquisa e Desenvolvimento, 85800-050, Toledo-Paraná, Brasil \\ *amandasabinonascimento@outlook.com \\ (Recebido em 31 de março de 2021; aceito em 22 de novembro de 2021)
}

\begin{abstract}
O trabalho teve por objetivo avaliar as características morfométricas e bioquímicas de cultivares de alface crespa em estufa e campo no Oeste do Paraná. O delineamento experimental foi de blocos ao acaso em esquema fatorial $2 \times 6$, com quatro repetições. O primeiro fator constou pelo ambiente de cultivo (estufa e campo) e o segundo, seis cultivares de alface da tipologia crespa (Camila, Isabela, Vanda, Vera, Pira Roxa e Scarlet). As avaliações morfométricas foram realizadas logo após do material vegetal, sendo quantificado a altura de planta, número de folhas, diâmetro da copa, massa fresca da parte aérea, massa fresca de folhas, área foliar e produtividade. Para as características bioquímicas, foram coletadas amostras de tecido foliar das cultivares de alface, em cada ambiente, devidamente identificadas, armazenadas e conduzidas para o laboratório onde foram avaliados teor de clorofila a, b e total, carotenoides, antocianina, acidez titulável, potencial hidrogeniônico e sólidos solúveis. Não foi constatada interação significativa entre as cultivares e os ambientes para as análises morfométricas. Entretanto, a cultivar Vanda apresentou produtividade superior em relação as demais. Em relação aos aspectos bioquímicos, para as variáveis clorofila a e clorofila total, foram observadas as maiores médias para a cultivar Scarlet em estufa. Para teores de antocianina, a cultivar Scarlet apresentou valores superiores a campo e em relação a estufa, a cultivar Pira roxa apresentou maiores teores de carotenoides. O cultivo em estufa proporcionou melhores condições para o cultivo de alface, promovendo de modo geral, resposta superior nas características morfológicas e bioquímicas.

Palavras-chave: produtividade, folhosas, ambiente controlado.
\end{abstract}

The objective of this work was to evaluate the morphometric and biochemical characteristics of lettuce cultivars in a greenhouse and field in western Paraná. The experimental design was randomized blocks in a $2 \times 6$ factorial scheme, with four replications. The first factor consisted of the cultivation environment (greenhouse and field) and the second, six lettuce cultivars of the crispy typology (Camila, Isabela, Vanda, Vera, Pira Roxa, and Scarlet). The morphometric evaluations were carried out right after the plant material, being quantified the plant height, number of leaves, canopy diameter, the fresh mass of aerial part, the fresh mass of leaves, leaf area, and productivity. For the biochemical characteristics, samples of leaf tissue of lettuce cultivars were collected in each environment, duly identified, stored, and taken to the laboratory where chlorophyll content a, b and total, carotenoids, anthocyanin, titratable acidity, hydrogen potential, and soluble solids. There was no significant interaction between cultivars and environments for morphometric analysis. However, the cultivar Vanda had higher productivity compared to the others. Regarding the biochemical aspects, for the variables chlorophyll a and total chlorophyll, the highest means were observed for the cultivar Scarlet in a greenhouse. For anthocyanin contents, the Scarlet cultivar showed higher values in the field, and in relation to the greenhouse, the Pira roxa cultivar showed higher carotenoid contents. The greenhouse cultivation provided better conditions for the cultivation of lettuce, promoting, in general, a superior response in the morphological and biochemical characteristics.

Keywords: productivity, hardwoods, controlled environment. 


\section{INTRODUÇÃO}

A alface (Lactuca sativa L.) é uma hortaliça da família Asteraceae, sendo considerada uma planta herbácea de caule pequeno e não ramificado, o qual se prendem as folhas que podem ser lisas ou crespas de coloração variadas [1]. Atualmente apresenta-se como uma das olerícolas de maior importância econômica no Brasil, com cerca de 35 mil hectares cultivados [2, 3]. Seu consumo tem aumentado a cada dia devido a mudanças no hábito alimentar do consumidor que procura por alimentos mais saudáveis.

Nos últimos anos foram registradas no Brasil, aproximadamente 380 cultivares desta hortaliça folhosa, sendo que o grupo crespa representa $70 \%$ do mercado nacional [4]. Esta diversidade de cultivares proporciona amplitude de formas, colorações, técnicas de cultivo e adaptabilidade ao cultivo em diferentes estações do ano. Apesar de ser cultivada em todas as regiões brasileiras, a cultura da alface apresenta restrições no seu cultivo, como as condições adversas de temperatura, umidade do ar e precipitação pluvial. Dessa forma, há uma diversificação de cultivares que são específicas para cada condição do ambiente de cultivo.

O potencial produtivo de espécies vegetais depende da interação do genótipo x ambiente, sendo assim, a escolha da cultivar é decisiva para o sucesso do sistema de cultivo adotado [5]. Bem como, cada cultivar responde às características intrínsecas da espécie e as condições meteorológicas do cultivo [5-7].

Neste sentido, uma tecnologia de grande utilidade empregada para a produção de hortaliça com alta produtividade e qualidade é a utilização de ambientes protegidos (estufas), por manter e propiciar condições favoráveis ao desenvolvimento da cultura. Essa técnica de cultivo é reconhecida como uma estratégia vantajosa por proteger a cultura dos fenômenos climáticos, além da proteção do solo contra lixiviação e regularidade na oferta do produto [5]. Entretanto, a ausência de cultivares selecionadas ou melhoradas para esse ambiente pode ser um fator limitante no desenvolvimento da cultura $[3,8]$.

Os ambientes protegidos permitem a realização de cultivos mesmo quando as condições externas são limitantes para o desenvolvimento da cultura. Sabe-se ainda que em ambientes controlados, a radiação solar do interior é reduzida em relação ao ambiente externo, ocorre

redução da produção de fotoassimilados, o que altera o metabolismo vegetal, como abertura estomática e eficiência do uso da água, entre outros [9]. Para ter-se eficiente funcionamento do metabolismo vegetal é necessário que ocorra absorção de luz de qualidade que chegue aos centros das reações para conversão em produtos fotossintéticos, que influenciam na produtividade da cultura [8].

A temperatura e densidade do fluxo de radiação solar que incide sobre as plantas podem ser diferentes de acordo com o ambiente de cultivo. Segundo Abade et al. (2019) [8] a variação de luminosidade, temperatura do ar e do solo é verificada em diferentes ambientes de cultivo em rúcula. Portanto, o ambiente de cultivo pode influenciar nas características qualitativas e quantitativas da cultura. Desta forma, o objetivo deste trabalho foi avaliar as características morfométricas e bioquímicas de cultivares de alface crespa em estufa em campo.

\section{MATERIAL E MÉTODOS}

O experimento foi realizado no período de janeiro a março de 2016, na estufa localizada no setor de cultivo protegido da Estação Experimental de Horticultura e Controle Biológico Prof. Dr. Mário César Lopes e no campo da Experimental Prof. Dr. Antônio Carlos dos Santos Pessoa, pertencente a Universidade Estadual do Oeste do Paraná (UNIOESTE), no Município de Marechal Cândido Rondon-PR, As estações estão localizadas nas coordenadas geográfica latitude $24^{\circ} 33^{\prime} 40^{\prime}$ ' S, longitude 540.' $14^{\prime}$ " W e altitude de $420 \mathrm{~m}$.

O clima da região segundo a classificação de Koppen é do tipo Cfa, subtropical mesotérmico úmido de inverno seco, com chuvas distribuídas em todo ano e verões quentes, com uma média anual de precipitação de $1700 \mathrm{~mm}$, mantendo a média anual de temperatura entre 22 e $23{ }^{\circ} \mathrm{C}$ [10]. O solo predominante é do tipo Latossolo vermelho eutroférrico.

O delineamento experimental adotado foi de blocos ao acaso em esquema fatorial $2 \times 6 \mathrm{com}$ quatro repetições. O primeiro fator constituiu-se de dos ambientes de cultivo (ambiente controlado 
e campo), sendo que a estufa apresentava uma estrutura de ferro galvanizado com teto em forma de arco, de dimensões $7 \times 30 \mathrm{~m}$ e 3,5 $\mathrm{m}$ de pé direito, com teto revestido com filme de polietileno de baixa densidade de $150 \mu \mathrm{m}$, com transmissividade à radiação solar de $80 \%$ e laterais fechadas com tela branca de $40 \%$ de sombreamento. O segundo fator constituiu-se de seis cultivares de alface crespa: Camila, Isabela, Vanda, Vera, Pira Roxa e Scarlet.

As sementes tratadas foram adquiridas comercialmente e a semeadura foi realizada em bandejas de poliestireno expandido de 200 células, contendo substrato agrícola comercial e estas permaneceram em casa de vegetação até apresentarem de três a quatro folhas verdadeiras (27-30 dias), sendo irrigadas conforme a necessidade da cultura até o momento de transplantio. Após, foram para os dois ambientes de cultivo, as mudas foram dispostas em parcelas experimentais constituídas de 16 plantas por parcela com espaçamento de $0,30 \times 0,30 \mathrm{~m}$, distribuídas em quatro linhas de plantio. A adubação de plantio e cobertura foi realizada com base na análise de solo e com as recomendações de [11]. A irrigação nos dois ambientes de cultivo foi realizada conforme a capacidade de solo de cada área.

A colheita e as avaliações nos dois ambientes de cultivo foram realizadas aos 30 dias após o transplante das mudas, sendo utilizado quatro plantas centrais de cada parcela. Para análise do desempenho bioquímico e produtivo realizou-se as seguintes avaliações: altura de planta $(\mathrm{cm})$ com e diâmetro da copa $(\mathrm{cm})$ com auxílio de régua, número de folhas, área foliar $\left(\mathrm{cm}^{2}\right)$, massa fresca da parte aérea $(\mathrm{g})$ e das folhas $(\mathrm{g})$. A produtividade estimada com base na massa fresca de plantas avaliadas no momento da colheita $\mathrm{kg} \mathrm{m}^{2}$.

A altura da planta foi medida com uma régua a partir do nível do solo até a extremidade da folha mais alta, o diâmetro da copa foi determinado com uma régua medindo as duas extremidades (diâmetro transversal e longitudinal da planta), onde posteriormente mediu-se copa da planta. A área foliar foi verificada por utilizando o aparelho Area Meter da marca Li-cor (3100C).

Após medição das variáveis morfométricas, foram coletadas uma amostra das folhas de aproximadamente $0,5 \mathrm{~g}$ de todos os tratamentos sendo identificadas, armazenadas em caixa térmica e conduzidas para o laboratório. Foi quantificado o teor dos pigmentos, clorofila a, b, "total" [12], carotenoides [13] e antocianina [14].

Para as análises químicas, as amostras foram maceradas com auxílio de almofariz e pistilo para a obtenção do suco onde posteriormente foi quantificado o teor de sólidos solúveis (SS) e o $\mathrm{pH}$, sob leitura direta do extrato do suco com auxílio de um refratômetro e peagâmetro digital, respectivamente. O teor de SS foi expresso em ${ }^{\circ}$ Brix. A acidez titulável (AT) foi determinada pelo método titulométrico de acordo com a metodologia proposta pelo Instituto Adolfo Lutz [15].

Após a realização das análises, os dados foram submetidos ao teste de normalidade de ShapiroWilk $(\mathrm{p} \leq 0,05)$. Em seguida, procedeu-se à análise de variância, sendo as médias comparadas pelo teste de Tukey $(\mathrm{p} \leq 0,05)$, utilizando programa estatístico GENES [16].

\section{RESULTADOS E DISCUSSÃO}

Conforme análise de variância, constatou-se que não houve interação significativa entre ambiente de cultivo e as cultivares para as variáveis altura de planta, número de folhas, área foliar, diâmetro de copa, massa fresca de parte aérea, massa fresca de folhas e produtividade (Tabela 1). De forma isolada, houve interação para o fator ambiente de cultivo e para as cultivares em todas as variáveis analisadas. 
Tabela 1: Valores médios para Altura de planta (AP), número de folha $(N F)$, área foliar (AF), diâmetro de copa $(D C)$, massa fresca da parte aérea (MFPA), massa fresca de folhas (MFF), produtividade $(P R O D)$ de cultivares de alface sob diferentes ambientes de cultivo. Marechal Cândido Rondon, UNIOESTE, 2016.

\begin{tabular}{cccccccc}
\hline Ambiente & $\begin{array}{c}\text { AP } \\
\mathrm{cm}\end{array}$ & $\mathbf{N F}$ & $\begin{array}{c}\mathbf{A F} \\
\mathrm{cm}^{2}\end{array}$ & $\begin{array}{c}\text { DC } \\
\mathrm{cm}\end{array}$ & $\begin{array}{c}\text { MFPA } \\
\mathrm{g}\end{array}$ & $\begin{array}{c}\text { MFF } \\
\mathrm{g}\end{array}$ & $\begin{array}{c}\text { PROD } \\
\mathrm{kg} \mathrm{m}^{2}\end{array}$ \\
\hline Campo & $12,32 \mathrm{~b}$ & $13,75 \mathrm{~b}$ & $4323,47 \mathrm{~b}$ & $25,25 \mathrm{~b}$ & $120,44 \mathrm{~b}$ & $104,17 \mathrm{~b}$ & $1,93 \mathrm{~b}$ \\
Estufa & $22,15 \mathrm{a}$ & $20,40 \mathrm{a}$ & $4900,48 \mathrm{a}$ & $35,24 \mathrm{a}$ & $217,42 \mathrm{a}$ & $184,88 \mathrm{a}$ & $3,48 \mathrm{a}$ \\
\hline DMS & 0,70 & 0,88 & 370,25 & 1,26 & 31,72 & 27,77 & 0,51 \\
\hline Cultivar & & & & & & & \\
\hline P. Roxa & $15,83 \mathrm{~b}$ & $17,22 \mathrm{a}$ & $4011,82 \mathrm{c}$ & $28,09 \mathrm{~b}$ & $141,84 \mathrm{~b}$ & $124,84 \mathrm{~b}$ & $2,27 \mathrm{~b}$ \\
Scarlet & $19,27 \mathrm{a}$ & $17,69 \mathrm{a}$ & $4234,36 \mathrm{bc}$ & $29,98 \mathrm{ab}$ & $126,27 \mathrm{~b}$ & $109,02 \mathrm{~b}$ & $2,02 \mathrm{~b}$ \\
Vera & $16,45 \mathrm{~b}$ & $16,97 \mathrm{a}$ & $4242,92 \mathrm{bc}$ & $33,85 \mathrm{a}$ & $187,55 \mathrm{ab}$ & $162,95 \mathrm{ab}$ & $3,00 \mathrm{ab}$ \\
Vanda & $19,50 \mathrm{a}$ & $19,33 \mathrm{a}$ & $5329,47 \mathrm{ab}$ & $32,83 \mathrm{a}$ & $241,33 \mathrm{a}$ & $204,12 \mathrm{a}$ & $3,86 \mathrm{a}$ \\
Isabela & $15,81 \mathrm{~b}$ & $18,95 \mathrm{a}$ & $6073,33 \mathrm{a}$ & $29,99 \mathrm{ab}$ & $189,64 \mathrm{ab}$ & $158,76 \mathrm{ab}$ & $3,03 \mathrm{ab}$ \\
Camila & $16,54 \mathrm{~b}$ & $12,32 \mathrm{~b}$ & $3779,97 \mathrm{c}$ & $26,75 \mathrm{~b}$ & $126,84 \mathrm{~b}$ & $107,47 \mathrm{~b}$ & $2,03 \mathrm{~b}$ \\
\hline DMS & 2,45 & 3,07 & 1291,96 & 4,41 & 81,68 & 71,49 & 1,31 \\
CV \% & 11,64 & 14,59 & 32,27 & 9,60 & 31,97 & 32,71 & 31,97 \\
\hline
\end{tabular}

*Médias seguidas da mesma letra, nas colunas, não diferem entre si pelo teste Tukey $(\mathrm{p} \leq 0,05)$.

Ao avaliar as características isoladas, observa-se para os parâmetros morfométricos sofrem influência do ambiente de cultivo, sendo o ambiente protegido significativamente superior ao campo em todas as variáveis analisadas (Tabela 1). Com exceção da área foliar, observou-se valores superiores para o cultivo de alface em ambiente protegido para as variáveis: altura, número de folhas, diâmetro de copa, massa fresca de folhas e da parte aérea e produtividade. Estas diferenças encontradas entre os ambientes comprovam que algumas caraterísticas são influenciadas pelo ambiente. Tais constatações corroboram com Silva et al. (2021) [17], que constataram que variedades de salsa cultivadas em malhas fotosseletivas preta e vermelha proporcionam plantas com mais folhas, maior altura e com maiores médias de massa fresca da parte aérea e consequentemente maior produtividade em relação ao ambiente não protegido.

Silva et al. (2020) [18] relatam que o ambiente protegido revestido com plástico de polietileno promove menores intensidades de radiações globais e refletidas, o que é favorável ao desenvolvimento da alface pois ameniza os efeitos da alta radiação solar, além de apresentar proteção física contra injurias climáticas, ataques de pragas e doenças, amplitude térmica e conservação da umidade do solo. Em trabalho realizado com cultivares de alface americana em ambiente protegido (túnel baixo) e campo aberto, Brzezinski et al. (2017) [3] concluíram que o ambiente protegido favorece o crescimento e a produção das cultivares de alface em relação ao campo aberto devido ao microclima gerado no interior do ambiente protegido com temperaturas e radiação solar amenas, além de manter a umidade relativa do ar adequada e reduzir os estresses causados pela alta velocidade do vento.

As cultivares Scarlet e Vanda apresentaram altura de planta superior em relação aos demais genótipos, já em relação ao número de folhas a cultivar Camila apresentou média de 12 folhas, sendo inferior as demais com médias de 16 a 19 folhas por planta. Estes resultados demostram que existe diferença genética entre as cultivares. Como as folhas são a parte comercializável da alface, é notório que a quantidade do número de folhas está diretamente relacionada a produtividade da cultura. Desta forma, pode-se observar que estas variáveis são características genéticas inerentes a cada cultivar [6].

As cultivares Isabela e Vanda apresentaram maior área foliar em relação às demais, já a Isabela, Vanda, Vera e Scarlet demostraram maior diâmetro de copa (Tabela 1). Essas variáveis estão diretamente relacionadas com a produtividade da cultura da alface, ainda que as cultivares tenham demostrado diferença entre elas, cada material genético pode responder de maneira distinta aos fatores do ambiente de cultivo. 
Para massa fresca de parte aérea, massa fresca de folhas e produtividade, a cultivar Vanda destaca-se com médias 241,33 g, 204,12 g e 3,86 kg m² respectivamente, mas não se diferencia estatisticamente de Vera e Isabela. Para massa fresca de parte aérea e massa fresca de folhas, os resultados obtidos no presente trabalho corroboram com o trabalho de Ferreira et al. (2007) [19] quando conduziram as cultivares Vera, Marisa e Simpson em ambiente protegido. Quanto a produtividade, os valores apresentam-se superiores aos de Ferreira et al. (2007) [19].

Coutinho et al. (2018) [6] ressaltam que estas respostas morfométricas podem estar relacionadas com a genética de cada cultivar, mas também podem ser influenciadas pelo ambiente de cultivo o qual acarreta mudanças fisiológicas e morfológicas das plantas.

Considerando os pigmentos fotossintetizantes, foi observado interação significativa $(p \leq 0,05)$ entre as cultivares de alface e os ambientes de cultivo, segundo os valores obtidos da clorofila $\alpha$, clorofila total, antocianinas e carotenoides (Tabela 2). $\mathrm{O}$ teor de clorofila b não apresentou interação significativa entre cultivares e ambiente de cultivo, sendo possível observar diferença significativa apenas entre os ambientes de cultivo (Tabela 3 ).

Tabela 2. Valores médios de clorofila $\alpha$, clorofila total, antocianinas, carotenoides, em função das cultivares e do ambiente de cultivo (ambiente protegido e a campo) de alface crespa. Marechal Cândido Rondon, UNIOESTE, 2016.

\begin{tabular}{|c|c|c|c|c|c|c|c|c|}
\hline \multirow{3}{*}{ Cultivar } & \multicolumn{2}{|c|}{ Clorofila $a$} & \multirow{2}{*}{\multicolumn{2}{|c|}{ Clorofila total }} & \multirow{2}{*}{\multicolumn{2}{|c|}{$\begin{array}{l}\text { Antocianina } \\
\qquad \mathrm{mg} \mathrm{g}^{-1}\end{array}$}} & \multirow{2}{*}{\multicolumn{2}{|c|}{$\begin{array}{c}\text { Carotenoide } \\
\text { mg g }^{-1}\end{array}$}} \\
\hline & \multicolumn{3}{|c|}{$\mathrm{mg} \mathrm{g}^{-1}$} & & & & & \\
\hline & Estufa & Campo & Estufa & Campo & Estufa & Campo & Estufa & Campo \\
\hline P. Roxa & $0,13 \mathrm{Ab}$ & $0,14 \mathrm{Aa}$ & $0,25 \mathrm{Ab}$ & $0,24 \mathrm{Aa}$ & $0,16 \mathrm{Ba}$ & $0,20 \mathrm{Ab}$ & $0,45 \mathrm{Aa}$ & $0,36 \mathrm{Bbc}$ \\
\hline Scarlet & $0,21 \mathrm{Aa}$ & $0,15 \mathrm{Ba}$ & $0,36 \mathrm{Aa}$ & $0,26 \mathrm{Ba}$ & $0,14 \mathrm{Bab}$ & $0,23 \mathrm{Aa}$ & $0,16 \mathrm{Bb}$ & $0,67 \mathrm{Aa}$ \\
\hline Vera & $0,12 \mathrm{Bb}$ & $0,14 \mathrm{Aa}$ & $0,23 \mathrm{Ab}$ & $0,24 \mathrm{Aa}$ & $0,10 \mathrm{Bcd}$ & $0,12 \mathrm{Ac}$ & $0,05 \mathrm{Bc}$ & $0,29 \mathrm{Ad}$ \\
\hline Vanda & $0,13 \mathrm{Ab}$ & $0,13 \mathrm{Aa}$ & $0,25 \mathrm{Ab}$ & $0,24 \mathrm{Aa}$ & $0,08 \mathrm{Ad}$ & $0,10 \mathrm{Ac}$ & $0,02 \mathrm{Bc}$ & $0,35 \mathrm{Abcd}$ \\
\hline Isabela & $0,11 \mathrm{Ab}$ & $0,13 \mathrm{Aa}$ & $0,24 \mathrm{Ab}$ & $0,25 \mathrm{Aa}$ & $0,12 \mathrm{Abc}$ & $0,10 \mathrm{Ac}$ & $0,08 \mathrm{Bc}$ & $0,39 \mathrm{Ab}$ \\
\hline Camila & $0,12 \mathrm{Ab}$ & $0,13 \mathrm{Aa}$ & $0,24 \mathrm{Ab}$ & $0,24 \mathrm{Aa}$ & $0,09 \mathrm{Bcd}$ & $0,12 \mathrm{Ac}$ & $0,05 \mathrm{Bc}$ & 0,31 Acd \\
\hline DMS & \multicolumn{2}{|c|}{0,0177} & \multicolumn{2}{|c|}{0,028} & \multicolumn{2}{|c|}{0,0216} & \multicolumn{2}{|c|}{0,0135} \\
\hline CV \% & \multicolumn{2}{|c|}{8,78} & \multicolumn{2}{|c|}{7,60} & \multicolumn{2}{|c|}{11,28} & \multicolumn{2}{|c|}{10,1} \\
\hline
\end{tabular}

*Médias seguidas pelas mesmas letras minúsculas na linha e maiúsculas na coluna não diferem estatisticamente entre si pelo teste de Tukey $(\mathrm{p} \leq 0,05)$.

Os resultados da interação entre cultivares e ambiente de cultivo para o teor de clorofila a mostram que as cultivares Pira Roxa, Vanda, Isabela e Camila não diferem entre o ambiente de cultivo. No entanto, Scarlet apresentou os maiores teores em estufa para clorofila $a$ e total, enquanto no campo as cultivares não diferiram entre si (Tabela 2).

Segundo estudo realizado por Abade et al. (2019) [8], a alta incidência de radiação solar em determinadas épocas do ano pode ser prejudicial para hortaliças folhosas, desta forma, alternativas que diminuam a incidência direta nas plantas são necessárias para que as mesmas tenham ganho em produção. Assim, a incidência da radiação solar pode ser maior ou menor de acordo com o ambiente de cultivo e consequentemente alterar o conteúdo de clorofilas.

Segundo estudo realizado por Rocha et al. (2019) [20], o estresse pode ser causado devido ao ambiente de cultivo, sendo necessário conhecer tanto a morfologia quanto as variáveis fisiológicas da planta como os pigmentos fotoprotetores. A clorofila a, por exemplo, é um pigmento de suma importância na planta pois apresenta-se na fase fotoquímica, enquanto os demais pigmentos auxiliam na absorção de luz e na transferência da energia para os centros de reação [21].

$\mathrm{O}$ teor de clorofila $\mathrm{b}$ foi influenciado pelo ambiente de cultivo, onde o maior teor foi observado quando as alfaces foram cultivadas em ambiente protegido. No entanto, as cultivares não diferiram entre si para esta variável (Tabela 3). Os teores de clorofila a e b se apresentam em quantidade diferente nas plantas e isso ocorre porque a proporção de clorofila a e b de forma geral é 3:1, porém varia de acordo com a espécie, idade da folha, localização da folha e da copa da planta [21]. 
Tabela 3. Valores médios de teor de clorofila b, sólidos solúveis, potencial hidrogeniônico ( $\mathrm{pH}$ ) e acidez titulável, em função das cultivares e ambiente de cultivo. Marechal Cândido Rondon, UNIOESTE, 2016.

\begin{tabular}{|c|c|c|c|c|}
\hline Ambiente & $\begin{array}{c}\text { Clorofila } b \\
\mathrm{mg} \mathrm{g}^{-1} \\
\end{array}$ & $\begin{array}{c}\text { Sólidos } \\
\text { Soluvéis } \\
{ }^{\circ} \text { Brix } \\
\end{array}$ & $\mathbf{p} \mathbf{H}^{\mathrm{na}}$ & $\begin{array}{c}\text { Acidez } \\
\text { Titulável }^{\mathrm{ns}} \\
\text { \% ác. Cítrico }\end{array}$ \\
\hline Campo & $0,11 \mathrm{~b}$ & $1,63 \mathrm{~b}$ & 6,62 & 0,07 \\
\hline Estufa & $0,13 \mathrm{a}$ & $1,81 \mathrm{a}$ & 6,49 & 0,07 \\
\hline DMS & 0,0024 & 0,03 & 0,15 & 0,0076 \\
\hline \multicolumn{5}{|c|}{ Cultivar } \\
\hline Pira Roxa & $0,11^{\mathrm{ns}}$ & $1,78^{\mathrm{ns}}$ & 6,59 & 0,08 \\
\hline Scarlet & 0,12 & 1,83 & 6,52 & 0,07 \\
\hline Vera & 0,12 & 1,82 & 6,50 & 0,07 \\
\hline Vanda & 0,11 & 1,65 & 6,61 & 0,07 \\
\hline Isabela & 0,11 & 1,64 & 6,55 & 0,07 \\
\hline Camila & 0,11 & 1,61 & 6,55 & 0,07 \\
\hline DMS & 0,0180 & 0,2106 & 0,3931 & 0,0196 \\
\hline $\mathrm{CV} \%$ & 10,28 & 8,38 & 4,03 & 17,49 \\
\hline
\end{tabular}

*Médias seguidas da mesma letra nas colunas, não diferem entre si pelo teste de Tukey a $5 \%$ de probabilidade.

As folhas utilizadas para realizar os teores dos pigmentos foram coletadas no mesmo dia em ambos os ambientes, sendo as plantas de mesma idade. A diferença, portanto, pode ter sido devido ao ambiente protegido proporcionar uma aceleração do crescimento e desenvolvimento das plantas, alterando o conteúdo deste pigmento.

Segundo estudo de Coutinho et al. (2020) [9], os pigmentos fotossintéticos, em especial os teores de clorofilas, são responsáveis pela conversão da radiação luminosa em energia, sob a forma de ATP e NADPH. Havendo assim, no decorrer do ciclo da cultura, um aumento da capacidade fotossintética das plantas, acréscimo este que se deve ao teor da ribulose-1,5bisfosfato carboxilase/oxigenase (Rubisco) [22].

Ao analisar o teor de clorofila total na Tabela 2, verifica-se que a única cultivar que apresentou redução á campo em comparação a estufa foi a cultivar Scarlet, as demais não diferem estatisticamente entre os ambientes. Scarlet também foi a única que apresentou aumento do teor de clorofila total em estufa. Estudos realizados por Pedrosa et al. (2011) [23] com 15 genótipos de alface, evidenciaram que os teores de clorofila variam entre as espécies, assim como entre genótipos de uma mesma espécie.

Teores maiores de clorofila total potencializam a atividade fotossintética que pode levar a incrementos relacionados as características agronômicas [24, 25], entretanto não foi observado incremento em massa fresca de parte aérea ou produtividade para a cultivar Scarlet, sendo esta semelhante estatisticamente as demais cultivares.

Em ambos os ambientes as cultivares Pira roxa e Scarlet (roxas) apresentaram os maiores valores para antocianina, visto que este é o pigmento responsável pela coloração roxa e é caracterizado como um flavonoide secundário que atua como um antioxidante no corpo [21]. De modo geral, os teores de antocianina foram mais representativos nas plantas cultivadas em campo, exceto as cultivares Vanda e Isabela que não diferem estatisticamente entre os dois ambientes.

Com exceção da Pira roxa, os maiores valores para carotenoides foram encontrados em cultivares conduzida em condições de campo. Dentre as cultivares, a Pira Roxa apresentou melhores resultados entre as demais no cultivo em estufa para esta variável. Em relação ao campo, a cultivar Scarlet obteve superioridade, sendo que a quantidade desse pigmento nas plantas está relacionada com os mecanismos preventivos e de defesa, quanto maior a concentração do carotenoide, melhor disposição de defesa da planta com o meio. O carotenoide é considerado um pigmento acessório juntamente com a clorofila $b$, auxilia na fotoproteção da clorofila $a$, maximizando a absorção de energia que atua efetivamente nas reações fotoquímicas [26]. 
O teor de sólidos solúveis apresentou um acréscimo, exclusivamente em plantas cultivadas em estufa, diferenciando-se entre as demais variáveis. Quando se analisou apenas as cultivares não foram observadas diferença entre elas.

Roversi e Masson (2004) [27], em trabalho realizado com alface Verônica (crespa) acondicionada em atmosfera modificada, verificaram variação de 3,8 a 4,2 ${ }^{\circ}$ Brix, sendo superiores aos valores descritos neste trabalho (Tabela 3). Segundo Alves et al. (2020) [26], esta variável pode ser influenciada pelo material genético, tipo de solo, condições climáticas, tratos culturais entre outros fatores podem influir na doçura do material vegetal.

Os teores de $\mathrm{pH}$ e acidez titulável não diferiram entre os ambientes de cultivo e nem entre as cultivares (Tabela 3). Os valores de $\mathrm{pH}$ e acidez titulável que determinam o sabor ácido ou azedo das hortaliças [26]. Resultados semelhantes aos apresentados neste trabalho são descritos por Bezerra Neto (2006) [28], onde a acidez titulável variou entre 0,06 e 0,07\% de ácido cítrico. Esses valores são os esperados para alface crespa (Tabela 3).

\section{CONCLUSÃO}

O ambiente de cultivo influencia as características morfométricas, produtivas e bioquímicas de alface crespa, sendo que em ambiente protegido (estufa) promove melhores desempenhos. As cultivares de alface crespa Vanda, Vera e Isabela apresentam maior produtividade em relação a P. roxa, Scarlet e Camila. Para o potencial bioquímico, as cultivares roxas Scarlett e Pira se destacaram em relação a Vera, Vanda, Scarlet e Camila.

\section{REFERÊNCIAS BIBLIOGRÁFICAS}

1. Bonett LP, Oliveira KM, Kabayashi GH, Gino BG, Magalhões HM, Cruz RMS. Produtividade da alface cv. Isabela ${ }^{\circledR}$ sob aplicação de fontes e doses de fertilizantes líquidos. Colloquium Agrariae. 2019 Ago;15(4):74-81. doi: 10.5747/ca.2019.v15.n4.a313

2. Neves JFNF, Nodari IDE, Seabra Júnior S, Dias LDE, da Silva LB, Dallacort R. Produção de cultivares de alface americana sob diferentes ambientes em condições tropicais. Rev Agro@ambiente On-line. 2016;10(2):130-136. doi: 10.18227/1982-8470ragro.v10i2.3200

3. Brzezinski CR, Abati J, Geller A, Werner F, Zucareli C. Produção de cultivares de alface americana sob dois sistemas de cultivo. Revista Ceres. 2017;64(1):83-9. doi: 10.1590/0034-737x201764010012

4. Sala FC, Costa CP. Retrospectiva e tendência da alfacicultura brasileira. Horticultura Bras. 2012 Abr;30:187-94. doi: 10.1590/S0102-05362012000200002

5. Gonçalves EDV, Dartora J, Mendonça HF, Rissato BB, Dildey ODF, Roncato S, et al. Crescimento e produtividade de cultivares de alface em ambiente protegido com e sem tela termorrefletora. Sci Agr Paranaensis. 2017;16(2):193-9.

6. Coutinho PW, Echer MM, Oliveira PS, Dalastra GM, Cadorin DA, Vanelli J. Productivity and qualitative characteristics of varieties of beets. J Agr Sci. 2018;10(6):327-33. doi: 10.5539/jas.v10n6p327

7. Coutinho PWR, Echer MM, Kestring K, Silva RH, Nascimento AS. Desempenho agronômico do alhoporró em diferentes densidades populacionais. Res Soc Develop. 2020;10(2):e13310212258. doi: 10.33448/rsd-v10i2.12258

8. Abade MTR, Klosowski ÉS, Rocha MEL, Coutinho PWR, Souza FLB, Barabasz RF. Morfometria de cultivares de rúcula sob telas de sombreamento e pleno sol na primavera. Agrometeoros. 2019;27(1):217-26. doi: 10.31062/agrom.v27i1.26578

9. Coutinho PWR, Echer MM, Guimarães VF, Lana MC, Inagaki AM, Brito TS, Alves TN. Photosynthetic efficiency of tomato plants submitted to calcium silicate application. J Neotr Agr. 2020;7(4):49-58. doi: 10.32404/rean.v7i4.4495

10. Alvares CA, Stape JL, Sentelhas PC, Gonçalves JLM, Sparovek G. Köppen's climate classification map for Brazil. Meteorologische Zeitschrift. 2013;22(6):711-28. doi: 10.1127/0941-2948/2013/0507

11. Trani PE, Passos FA, Tavares M, Azevedo Filho JA. Hortaliças. In: Raij B, Cantarela H, Quaggio JA, Furlani AMC, editores. Recomendações de adubação e calagem para o Estado de São Paulo. Campinas (SP): Instituto Agronômico \& Fundação IAC; 1996. p. 155-185.

12. Sims DA, Gamon JA. Relationships between leaf pigment content and spectral reflectance across a wide range of species, leaf structures and developmental stages. Remote Sensing Environm. 2002;81(23):337-54. doi: 10.1016/S0034-4257(02)00010-X 
13. Nagata M, Yamashita I. Simple method for simultaneous determination of chlorophyll and carotenoids in tomato fruit. Nippon Shokuhin Kogyo Gakkaishi. 1992;39(10):925-8. doi: $10.3136 /$ nskkk1962.39.925

14. Lopes TJ, Xavier MF, Quadri MGN, Quadri MB. Antocianinas: Uma breve revisão das características estruturais e da estabilidade. Rev Brasa Agroci. 2007;13(3):291-7. doi: 10.18539/CAST.V1313.1375

15. Instituto Adolfo Lutz - IAL. Métodos físico-químicos para análise de alimentos. São Paulo: Instituto Adolfo Lutz; 2008.

16. Cruz CD. Programa genes: aplicativo computacional em genética e estatística. Viçosa (MG): UFV; 2001.

17. Silva LCV, Souza GS, Braulio CS, Santos AR, Santos JS, Oliveira AS, Oliveira EC, Fiuza Júnior FJS. Características comerciais em variedades de salsa cultivadas sob diferentes ambientes de luz. Braz J Develop. 2021;7(1):5705-13. doi: 10.34117/bjdv7n1-388

18. Silva MT, Morselli TBGA, Morselli LA, Schubert RN, Matoso ES, Simon EDT, et al. Húmus de minhoca (Eisenia foetida) na adubação de alface em ambiente protegido. Braz J Develop. 2020;6(4):17549-57. doi: 10.34117/bjdv6n4-067

19. Ferreira RLF, Araújo N, Sebastião E, Silva SS, Abud EA, Kusdra JF. Cultivo orgânico de alface em campo e em casa de vegetação com diferentes tipos de cobertura de solo. Rev Bras Agroecol. 2007;2:1510-4.

20. Rocha MEL, Coutinho PWR, Abade MTR, Inagaki AM, Cadorin DA, Hoepers LML. Morfofisiologia de plantas de couve manteiga sob concentrações de húmus líquido. Rev Ciências Agrovet. 2019;18(4):438-43. doi: 10.5965/223811711842019438

21. Taiz L, Zeiger E, Moller IM, Murphy A. Plant physiology and development. 6. ed. Sunderland: Sinauer Associates; 2017.

22. Echer MM, Guimarães VF, Inagaki AM, Dalastra GM, Hachmann TL. Photosynthetic pigments and gas exchange in red and green cabbage under no-tillage and conventional systems. Rev Ci Agr. 2020;51(2):1-10. doi: 10.5935/1806-6690.20200037

23. Pedrosa CE, Andrade Júnior VC, Pinto Navd, Castro BMC, Azevedo AM, Oliveira CM, et al. Quantificação de componentes bromatológicos de genótipos de alface sob cultivo protegido. Horticultura Bras. 2011;29: S5090-S5097.

24. Liu C, Liu Y, Lu Y, Liao Y, Nie J, Yuan X, et al. Use of a leaf chlorophyll content index to improve the prediction of above-ground biomass and productivity. Peer J. 2019;6:e6240. doi: 10.7717/peerj.6240

25. Pane C, Palese AM, Celano G, Zaccardelli M. Effects of compost tea treatments on productivity of lettuce and kohlrabi systems under organic cropping management. Italian J Agron. 2014;9(3):153-6. doi: 10.4081/ija.2014.596.

26. Alves TN, Echer MM, Coutinho PWR, Macedo Júnior EK, Klosowski ÉS, Sackser GAB, et al. Efeitos dos consórcios com quiabeiro nas características físico-químicas da couve de folha sob manejo orgânico. Braz J Develop. 2020;6(10):79987-80001. doi: 10.34117/bjdv6n10-430

27. Roversi RM, Masson ML. Qualidade da alface crespa minimamente processada acondicionada em atmosfera modificada. Ciência e Agrotecnologia. 2004;28(4):823-30. doi: 10.1590/S141370542004000400014

28. Bezerra Neto F, Barros Júnior AP, Silva EO, Negreiros MZ, Oliveira EQ, Silveira LM, et al. Qualidade nutricional de cenoura e alface cultivadas em Mossoró-RN em função da densidade populacional. Horticultura Bras. 2006;24(4):476-80. doi: 10.1590/S0102-05362006000400016 